\title{
Dental considerations for the patient with diabetes
}

\author{
Silvia Martí Álamo ${ }^{1}$, Yolanda Jiménez Soriano ${ }^{2}, M^{\mathrm{a}}$ Gracia Sarrión Pérez $^{3}$ \\ ${ }^{1}$ Dentist. \\ ${ }^{2}$ Assistant Professor Doctor. Department of Stomatology. Medicine and dentistry faculty. Valencia University.
}

Correspondence:

San Vicente mártir st., 102, 20

46007 Valencia

E-mail: silviamartialamo@hotmail.es

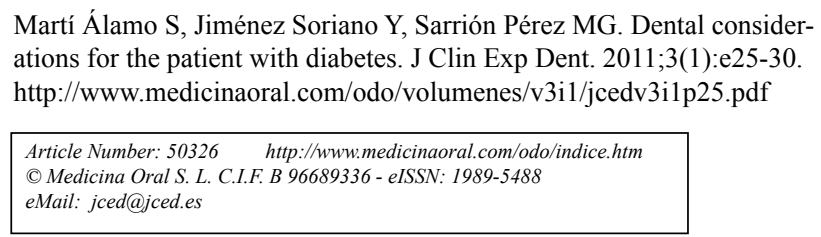

\begin{abstract}
Diabetes mellitus (DM) is one of the most frequent pathologies that dentists encounter, due to its high prevalence worldwide. It is diagnosed by the repeated obtaining of fasting plasma glucose levels of $126 \mathrm{mg} / \mathrm{dl}$ or higher, or glycosylated hemoglobin of 6' $5 \%$ or higher. Diabetes (especially if it is not well controlled) brings with it a greater risk of periodontal disease, which is the most frequent complication. On the other hand, the possible influence of periodontal disease on glycemic control is still not well established. Other reported manifestations are xerostomia, sialadenosis and burning mouth syndrome. With regard to dental caries, oral lichen planus and candidosis, recent studies have not revealed a significantly higher incidence in these patients.

For dental treatment, the type of diabetes suffered, the treatment given for the disease, and the glycemic control status (using the glycosylated hemoglobin test) should be known. Patients should receive short morning appointments to reduce stress. The dentist has to be aware of the possible occurrence of an acute complication (hypoglycemia or hyperglycemia). Furthermore, these patients suffer from delayed wound healing and major susceptibility to infections.
\end{abstract}

Key words: Diabetes, dental management, periodontal disease, dental considerations. 


\section{Introduction}

Diabetes mellitus (DM) is one of the most frequent pathologies that dentists encounter. Its clinical importance springs from the possible occurrence of acute complications, whose severity could mean an immediate risk for the diabetic patient's life and require urgent diagnosis and treatment (1).

DM includes a group of diseases characterized by impaired action or secretion of insulin, or both. There are four etiologic types of diabetes, although the most frequent are type $1(90 \%)$ and $2(5-10 \%)$ (2). Prevalence of diabetes in adults worldwide was estimated to be $4 \%$ in 1995 , and is predicted to rise to $5^{\prime} 4 \%$ by the year 2025 . The countries with the largest number of people with diabetes are India, China and the U.S. In developing countries, the majority are in the age range of 45-64 years. In the developed countries, the majority of people with diabetes are aged 65 years. There are more women than men with diabetes (3).

Poorly controlled diabetes could lead to complications that may even be life- threatening. Long- term complications include: retinopathy, nephropathy, autonomic neuropathy, peripheral neuropathy and cardiovascular disease $(2,4)$.

The dentist plays a major role with other members of the health team in helping a patient maintain glycemic control by achieving optimal oral health; and by referring undiagnosed patients with complications suggestive of diabetes to physicians for further evaluation (5).

\section{Objectives}

The objectives of this paper are: firstly, to do a review of literature about diabetes mellitus, and the repercussions of the disease in dentistry; and, secondly, to summarize the management strategies that can be put into practice in the dental office to treat these patients.

\section{Material and Methods}

For this review, we selected articles from the PubMedMedline database. We searched for them using key words controlled by MeSh, all of them referred to diabetes, its complications and considerations for the dental management. The following limits were utilized: articles written in Spanish or in English and published in the 1993- 2010 period. A total of 25 articles were chosen: 8 reviews of literature ( 1 of them being a systematic review); 7 transversal studies; 2 meta- analysis; 3 panels of experts; 2 clinical cases; 1 randomized clinical assay; 1 letter to the editor and 1 case- control study.

\section{Results}

Oral manifestations. Periodontal disease is the most frequent oral complication of diabetes, as reported by Löe (6) in 1993, who referred to it as "the sixth complication of diabetes mellitus" (the other five complications are: retinopathy, nephropathy, microvascular disease and peripheral vascular disease) (4).

A patient with poorly controlled diabetes has a major risk of developing periodontal disease $(5,7)$, which will start as gingivitis and gradually, if the glycemic control is deficient, this may progress to an advanced periodontitis. Diabetic children and adults without proper control of their diabetes show a tendency to present higher gingival indexes. Besides, several studies have demonstrated that patients with poorly controlled type $1 \mathrm{DM}$ have more advanced and severe periodontal disease than patients with an adequate glycemic control; this could be due to the association found between poorer glycemic control and elevated gingival crevicular fluid interleukin-1 $\beta$ (7).

Several mechanisms have been proposed which may explain how diabetes produces alterations in the organs and tissues, including the periodontium. First studies demonstrated that the advanced glycation end- products (AGE) synthesized due to hyperglycemia, can convert macrophages into cells with a destructive phenotype, producing high levels of interleukin-1 $\beta$, interleukin 6 (IL-6) and tumour necrosis factor- $\alpha$ (TNF- $\alpha$ ). Moreover, AGE have the capacity to increase the endothelium permeability and express high levels of molecular adhesion receptors. These changes could explain the greater susceptibility to infections and the delayed wound healing in diabetic patients (8). This depressed immune response could explain why it may not be possible to eradicate periodontal infection totally in diabetics after conventional periodontal therapy. This might be one of the reasons why antibiotics may be suggested with mechanical therapy for diabetic patients, especially for uncontrolled cases (7). By contrast, in trying to determine the capacity of periodontal disease to adversely affect the control of diabetes by influencing gylcemia levels, it has been hypothesized that chronic low grade inflammations such as this might result in insulin resistance (9).

Some studies report that specific treatment of periodontal disease in diabetic patients may improve their glycemic control. Nevertheless, the evidence currently available does not provide sufficient information on which to confidently base any clinical recommendations $(10,11$, 12). This has motivated the preparation of a randomized and controlled trial which will provide evidence- based recommendations for clinicians (DIAPERIO trial, whose definitive results will be published in 2013) (12).

The relationship between DM and dental caries has been studied, but it has not been possible to establish a clear association between these conditions. The results obtained vary considerably depending on the study; some of them found a higher prevalence of caries in diabetic patients $(13,14)$, some found lower $(15)$, while other reported no difference (16).

Diabetic patients sometimes complain of having a dry mouth (xerostomia), which can be due to thirst, a fre- 


\section{CRITERIA FOR THE DIAGNOSIS OF DIABETES}

\begin{tabular}{|l|l|l|}
\hline \multicolumn{1}{|c|}{ MEASUREMENT } & $\begin{array}{c}\text { DIAGNOSTIC VALUES } \\
\text { FOR DIABETES }\end{array}$ & \multicolumn{1}{c|}{ CHARACTERISTICS } \\
\hline $\begin{array}{l}\text { Glycosylated hemoglobin } \\
\text { (HbA1c) }\end{array}$ & $\geq 6.5 \%$ & $\begin{array}{l}\text { The test should be performed in a laboratory } \\
\text { using the standarized method. It reflects average } \\
\text { blood glucose levels over a 2- to 3-month period } \\
\text { of time }\end{array}$ \\
\hline Fasting plasma glucose & $\geq 126 \mathrm{mg} / \mathrm{dl}(7.0 \mathrm{mmol} / 1)$ & $\begin{array}{l}\text { Fasting is defined as no caloric intake for } 8 \\
\text { hours }\end{array}$ \\
\hline $\begin{array}{l}\text { Postprandrial plasma glucose } \\
(2 \text { hours after caloric intake })\end{array}$ & $\geq 200 \mathrm{mg} / \mathrm{dl}(11.1 \mathrm{mmol} / 1)$ & $\begin{array}{l}\text { The test should be performed as described by } \\
\text { the World Health Organization, using a glucose } \\
\text { load containing the equivalent of } 75 \mathrm{~g} \text { anhydrous } \\
\text { glucose dissolved in water }\end{array}$ \\
\hline Random plasma glucose & $\geq 200 \mathrm{mg} / \mathrm{dl}(11.1 \mathrm{mmol} / 1)$ & \\
\hline
\end{tabular}

Table 1. Criteria for the diagnosis of diabetes (American Diabetes Association, 2010) (2)

quent manifestation of diabetes (16). In a study carried out on 40 adult type 2 diabetic patients, it was possible to assess objectively, using scintigraphy of the salivary glands, that there was an actual alteration in the salivary glands' function (17). A different study revealed an alteration in the secretory capacity of the salivary glands in adults with poorly controlled diabetes, compared to well controlled diabetic patients and nondiabetic patients, although they did not refer xerostomia (18).

Sialadenosis is an asymptomatic bilateral parotid gland enlargement quite common in diabetes (especially type 2). It has also been reported in alcoholism with liver pathology, and in chronic malnutrition (19). It is considered a metabolic or degenerative pathology (not inflammatory or tumoral). The most accepted etiopathogenic theory posits the existence of a disturbance in the autonomic sympathetic innervation, that leads to a dysregulation of protein synthesis and/ or its secretion. Cytoplasmic swelling develops from engorgement of intracytoplasmic zymogen granules. As a result, the parotid's acini, which normally measure $40 \mu \mathrm{m}$ in diameter, increases to as much as $100 \mu \mathrm{m}$. This enlargement causes the clinically visible glandular hypertrophy (19). It has also been reported that parotid enlargement in diabetic patients could be a consequence of lipid infiltration, due to the alteration in the lipidic metabolism in diabetes (20). In any case, sialadenosis does not require treatment (19). In diabetic patients, the presence of Candida species in the oral cavity is greater than in non diabetic patients; however, candidal infection -candidosis- may not be significantly higher, not even in individuals with a poorly controlled diabetes. The mechanism by which diabetes predisposes a high oral presence of Candida is not yet established (21), although it is believed that the reasons could be salivary dysfunction, immunosuppression and high salivary glucose levels (5). However, it is widely recognized that high salivary glucose levels in diabetic patients favour yeast growth (21).

DM is considered one of the systemic causes of burning mouth syndrome (BMS). The latest studies of this pathology suggest that the cause is a peripheral neuropathy (16). Moore et al. (22), in a study carried out on 371 adult patients with type $1 \mathrm{DM}$, concluded that the majority of diabetic patients with BMS were mainly women who had developed a peripheral neuropathy due to their DM. This, and other similarities found between BMS and the peripheral neuropathy, suggests that a neuropathic process could be the underlying cause of BMS (22).

An association between DM and oral lichen planus has been described in literature, but has not been seen consistently in all populations of individuals with diabetes (16). For that reason, there appears to be no relationship between lichen planus and diabetes mellitus (5).

Loss of joint flexibility and increased stiffness are common clinical findings in DM. At the extreme end of these manifestations, they affect the extra- articular tissues, resulting in significant deformity and inflexibility of joints -"diabetic cheiroarthropathy"-. Temporomandibular joint dysfunction has not been studied specifically in diabetic patients, but since DM is a metabolic disorder, all joints may be susceptible (4). The association of osteoporosis with type $1 \mathrm{DM}$ is well- established. But for patients with type $2 \mathrm{DM}$ this relationship is still unclear, although there is an increased risk of fracture attributed to falls due to hypoglycemia (4).

Dental considerations. Prior to dental treatment, the dentist must obtain a complete medical history, which indicates the type of diabetes suffered and complica- 
tions, the treatment received and the status of diabetes control. The recent consensus of the American Diabetes Association and the European Association for the Study of Diabetes (2009) (23) advocate glycated hemoglobin as the main parameter to assess the metabolic control. As a rule, a $\mathrm{HbA} 1 \mathrm{c}<7 \%$, a preprandial glycemia of $70-130 \mathrm{mg} / \mathrm{dl}$ and a postprandial glycemia $<180 \mathrm{mg} /$ $\mathrm{dl}$ are indicative of good metabolic control. The wellcontrolled diabetic patient can be treated similarly to a nondiabetic patient, preferably receiving short morning appointments to reduce stress. They must not fast, in order to prevent hypoglycemia (1).

Within the sphere of the dental office, we can consider two kinds of complications in these patients. First, the acute complications -which can break out during the appointment- which are hypoglycemia and hyperglycemia (1). With respect to the chronic complications of diabetes of interest in this case, there are some systemic (like neuropathy, nephropathy and cardiovascular diseases) $(1,2,4)$, and some affecting the stomatognathic area, like periodontal disease $(6,8)$, sialadenosis $(18)$, burning mouth syndrome (17), and osteoporosis and possible dysfunction of the temporomandibular joint (5). We should be aware of the increased susceptibility of these individuals to infections and delayed wound healing (9).

Dental management of diabetes. When a dental treatment is going to be performed, some considerations must be taken into account. These would be appreciably different depending on the type of diabetes suffered. In this paper we analyze type 1 and 2 diabetes, the most prevalent forms.

- Type 1 diabetic patients undergoing a dental procedure (1): follow the considerations previously described.

- Non- invasive dental procedures: well- controlled patients can be treated similarly to nondiabetic individuals. Be aware of the increased susceptibility of these patients to infections and delayed wound healing. In poorly controlled patients, delay the dental treatment if possible until they have achieved good metabolic control.

- Invasive dental procedures: patients should ask their doctor for instructions concerning their medication (normally, if they have metabolic stability, they should take half their daily dose of insulin the morning of the treatment; then, after the intervention, the whole dose should be taken with a supplement of rapid-acting insulin). Blood glucose should be measured preoperatively. If it is between 100 and $200 \mathrm{mg} / \mathrm{dl}$, the invasive dental procedure can be performed. If blood glucose is $>200 \mathrm{mg} / \mathrm{dl}$, an intravenous infusion of $10 \%$ dextrose in half- normal saline is initiated, and rapid- acting insulin is administered subcutaneously. If the treatment lasts more than 1 hour, blood glucose should be measured hourly. If blood glucose is $>200$ $\mathrm{mg} / \mathrm{dl}$, rapid acting- insulin should be administered subcutaneously.

Type $1 \mathrm{DM}$ is considered a risk factor with regard to suffering infection. For that reason, when invasive dental procedures are going to be performed (as intra ligamentous anesthesia, teeth extractions, biopsies, etc.), the usual guidelines for the antibiotic prophylaxis should be followed (24).

- Type 2 diabetic patients undergoing a dental procedure (1): follow the considerations previously described.

- Non- invasive dental procedures: people who control their disease well by diet and exercise require no special perioperative intervention. As in type 1 diabetic patients, be aware of their susceptibility to infections and delayed wound healing. In poorly- controlled patients, delay the dental treatment if possible until they have achieved good metabolic control.

- Invasive dental procedures: patients should ask their doctor for instructions regarding their medication (normally, those patients being treated with oral hypoglycemic agents should take their normal dose in the morning and eat their regular diet).

Acute complications. Hypoglycemia is the major issue that confronts dental practitioners when treating diabetic patients, particularly if patients are fasting (4). The clinical presentation of hypoglycemia is very similar to hyperglycemia. If in doubt, it should be treated as a hypoglycemia. The characteristics and treatment of this complication are showed in Table 2 (4).

Hypoglycemia usually appears in response to the stress experienced before, during or after the treatment, and has been shown to cause a significant increase in perioperative morbidity and mortality (1). The stress response is characterized by acute metabolization of carbohydrates, proteins and fats to provide increased levels of glucose, which is necessary as a major fuel source to the vital organs. In addition, resistance to the effects of insulin increase (1). There are no specific guidelines regarding which levels of hyperglycemia are dangerous or how it should be managed before or during the procedure, so if the patient is conscious and can follow other instructions, it is prudent to continue with the treatment (4).

Chronic complications. The possible cardiovascular complications of diabetes should be properly assessed before dental treatment. Autonomic neuropathy can predispose to orthostatic hypotension, respiratory arrest or hemodynamic instability. If the patient has renal complications, a dose adjustment of the drugs should be performed, using the creatinin clearance (1). It is recommended to associate antibiotic treatment when mechanical periodontal treatment is performed, and also administer an antibiotic prophylaxis $(7,25)$. Osteoporosis present in type $1 \mathrm{DM}$ requires great care when performing surgery, in order to prevent iatrogenic fractures (4). Due to the delayed healing response in diabetic patients $(8,25)$, 


\begin{tabular}{|c|c|}
\hline \multicolumn{2}{|c|}{ IDENTIFICATION AND TREATMENT OF HYPOGLYCEMIA } \\
\hline \multicolumn{2}{|l|}{ IDENTIFICATION } \\
\hline Symptoms & Signs \\
\hline $\begin{array}{l}\text { - Shakiness } \\
\text { - Anxiety } \\
\text { - Increased sweating } \\
\text { - Hunger }\end{array}$ & $\begin{array}{l}- \text { Tremors } \\
\text { - Tachycardia } \\
\text { - Altered consciousness (lethargy and obtundation or per- } \\
\text { sonality change) } \\
\circ \text { Blood glucose level: }<60 \mathrm{mg} / \mathrm{dl}\end{array}$ \\
\hline \multicolumn{2}{|l|}{ TREATMENT } \\
\hline Conscious patient & Unconscious patient \\
\hline $\begin{array}{l}\text { - Administer } 15 \mathrm{mg} \text { of simple carbohydrates } \\
\text { - Repeat finger- stick glucose test in } 15 \text { minutes: } \\
\text { - Blood glucose level }>\mathbf{6 0} \mathbf{~ m g / d l : ~ p a t i e n t ~ s h o u l d ~ b e ~} \\
\text { asked to eat or drink (for example, a sugar-sweetened } \\
\text { beverage) } \\
\text { Blood glucose level }<\mathbf{6 0} \mathbf{~ m g / d l} \text { : repeat treatment of } \\
15 \mathrm{~g} \text { of simple carbohydrates and check blood glucose } \\
\text { in } 15 \text { minutes. Continue until achieving a blood gluco- } \\
\text { se level }>60 \mathrm{mg} / \text { dl } \\
\text { - Ask the patient to notify his/ her physician }\end{array}$ & $\begin{array}{l}\text { With intravenous access: } \\
\text {-Administer } 5 \text { to } 25 \mathrm{~g} \text { of } 50 \% \text { dextrose immediately } \\
\text { - Notify the patient's physician } \\
\text { Without intravenous access: } \\
\text {-Apply glucose gel inside the mouth in a semiobtund pa- } \\
\text { tient or treat with } 1 \mathrm{mg} \text { of glucagon intramuscularly or } \\
\text { subcutaneously } \\
\text { - Repeat the blood glucose test in } 15 \text { minutes } \\
\text { - Establish intravenous access and notify the patient's } \\
\text { physician }\end{array}$ \\
\hline
\end{tabular}

Table 2. Identification and treatment of hypoglycemia in the dental office.

implant therapy is still controversial and at the moment, there is a lack of definitive guidelines. In any case, these individuals could be candidates for the placement of dental implants if they have good control of their metabolism. There is general agreement in advocating the use of prophylactic antibiotics in diabetic patients (25).

\section{Conclusions}

Periodontal disease is the main oral clinical manifestation in diabetic patients. Furthermore, burning mouth syndrome, the sensation of a dry mouth and and sialadenosis have been attributed to the disease.

With these patients, we should be aware of their increased susceptibility to infections and delayed wound healing. Well- controlled diabetics can be treated in the dental office similarly to nondiabetic patients, but morning appointments are preferable, and patients should be instructed not to fast, in order to reduce the risk of the occurrence of hypoglycemia.

\section{References}

1. Bergman SA. Perioperative management of the diabetic patient. Oral Surg Oral Med Oral Pathol Oral Radiol Endod. 2007;103:731-7.

2. American Diabetes Association. Diagnosis and classification of diabetes mellitus. Diabetes Care. 2010;33:62-9.

3. King H, Aubert RE, Herman WH. Global burden of diabetes, 19952025: prevalence, numerical estimates, and projections. Diabetes Care. 1998;21:1414-31.

4. Kidambi S, Patel SB. Diabetes mellitus: considerations for dentistry. J Am Dent Assoc. 2008;139:8S-18S.
5. Vernillo AT. Dental considerations for the treatment of patients with diabetes mellitus. J Am Dent Assoc. 2003;134:24S-33S.

6. Löe H. Periodontal disease. The sixth complication of diabetes me1litus. Diabetes Care. 1993;16:329-34.

7. Tan WC, Tay FB, Lim LP. Diabetes as a risk factor for periodontal disease: current status and future considerations. Ann Acad Med Singapore. 2006;35:571-81.

8. Kaur G, Holtfreter B, Rathmann W, Schwahn C, Wallaschofski H, Schipf S, et al. Association between type 1 and type 2 diabetes with periodontal disease and tooth loss. J Clin Periodontol. 2009;36:765-74.

9. Fernández-Real JM, López-Bermejo A, Vendrell J, Ferri MJ, Recasens M, Ricart W. Burden of infection and insulin resistance in healthy middle-aged men. Diabetes Care. 2006;29:1058-64.

10. Darré L, Vergnes JN, Gourdy P, Sixou M. Efficacy of periodontal treatment on glycaemic control in diabetic patients: A meta-analysis of interventional studies. Diabetes Metab. 2008;34:497-506.

11. Janket SJ, Wightman A, Baird AE, Van Dyke TE, Jones JA. Does periodontal treatment improve glycemic control in diabetic patients? A meta-analysis of intervention studies. J Dent Res. 2005;84:1154-9.

12. Vergnes JN, Arrivé E, Gourdy P, Hanaire H, Rigalleau V, Gin H, et al. Periodontal treatment to improve glycaemic control in diabetic patients: study protocol of the randomized, controlled DIAPERIO trial. Trials. 2009;10:65.

13. Miralles L, Silvestre FJ, Hernández-Mijares A, Bautista D, Llambes F, Grau D. Dental caries in type 1 diabetics: influence of systemic factors of the disease upon the development of dental caries. Med Oral Patol Oral Cir Bucal. 2006;11:E256-60.

14. Arrieta-Blanco JJ, Bartolomé-Villar B, Jiménez-Martínez E, Saavedra-Vallejo P, Arrieta-Blanco FJ. Bucco-dental problems in patients with Diabetes Mellitus (I): Index of plaque and dental caries. Med Oral. 2003;8:97-109.

15. Siudikiene J, Machiulskiene V, Nyvad B, Tenovuo J, Nedzelskiene I. Dental caries and salivary status in children with type 1 diabetes mellitus, related to the metabolic control of the disease. Eur J Oral Sci. 2006;114:8-14. 
16. Ship JA. Diabetes and oral health: an overview. J Am Dent Assoc. 2003;134:4S-10S.

17. Kao CH, Tsai SC, Sun SS. Scintigraphic evidence of poor salivary function in type 2 diabetes. Diabetes Care. 2001;24:952-3.

18. Chávez EM, Borrell LN, Taylor GW, Ship JA. A longitudinal analysis of salivary flow in control subjects and older adults with type 2 diabetes. Oral Surg Oral Med Oral Pathol Oral Radiol Endod. 2001;91:166-73.

19. Mandel L, Patel S. Sialadenosis associated with diabetes mellitus: a case report. J Oral Maxillofac Surg. 2002;60:696-8.

20. Carda C, Carranza M, Arriaga A, Díaz A, Peydró A, Gomez de Ferraris ME. Structural differences between alcoholic and diabetic parotid sialosis. Med Oral Patol Oral Cir Bucal. 2005;10:309-14.

21. Soysa NS, Samaranayake LP, Ellepola AN. Diabetes mellitus as a contributory factor in oral candidosis. Diabet Med. 2006;23:455-9.

22. Moore PA, Guggenheimer J, Orchard T. Burning mouth syndrome and peripheral neuropathy in patients with type 1 diabetes mellitus. J Diabetes Complications. 2007;21:397-402.

23. Nathan DM, Buse JB, Davidson MB, Ferrannini E, Holman RR, Sherwin R, et al. Medical management of hyperglycemia in type 2 diabetes: a consensus algorithm for the initiation and adjustment of therapy: a consensus statement of the American Diabetes Association and the European Association for the Study of Diabetes. Diabetes Care. 2009;32:193-203

24. Gutiérrez JL, Bagán JV, Bascones A, Llamas R, Llena J, Morales A, et al. Consensus document on the use of antibiotic prophylaxis in dental surgery and procedures. Med Oral Patol Oral Cir Bucal. 2006;11:188-205

25. Beikler T, Flemmig TF. Implants in the medically compromised patient. Crit Rev Oral Biol Med. 2003;14:305-16. 